\title{
Endophytic Fungi Found in Association with Bacopa monnieri As Potential Producers of Industrial Enzymes and Antimicrobial Bioactive Compounds
}

\author{
Meenu Katoch*, Aseem Salgotra and Gurpreet Singh \\ Microbial Biotechnology Department; Indian Institute of Integrative Medicine Canal Road; Jammu - India
}

\begin{abstract}
This study aimed to screen the endophytic fungal species of ethano-medicinal plant Bacopa monnieri (L.) Pennell for their ability to produce antimicrobial substances against Bacillus subtilis, Pseudomonas aeroginosa, Salmonella typhimurium, Escherichia coli, Klebsiella pneumonia, Staphylococcus aureus, and Candida albicans. Endophytes were also screened for their ability to produce amylase, cellulase, protease and lipase to evaluate their ecological role within the host plant. Twenty-six endophytes were isolated and seventeen were identified. All the isolated endophytes exhibited amylolytic activity. Lipolytic, cellulolytic, proteolytic activity was shown by 98,28 and $31 \%$ isolates, respectively. Similarly, all the endophytes (100\%) exhibited significant antimicrobial activity against $\mathrm{K}$. pneumonia, while seventeen endophytes (89.5\%) were active against S. aureus. Fourteen endophytes (78.9\%) showed significant antimicrobial activity against B. subtilis and C. albicans. Eleven (57.8\%), nine (50\%), four (21\%) endophytes were active against $\mathrm{S}$. typhimurium, E. coli and $\mathrm{P}$. aeruginosa, respectively.
\end{abstract}

Key words: Bacopa monnieri, Antimicrobial, ITS 5.8S rDNA, lipase, amylase, endophyte

\section{INTRODUCTION}

In recent times, there has been increasing demand for the products from more sustainable sources and to avoid synthetic molecules, which is essentially driven by the increasing health consciousness of the society. Similarly, focus is also towards the microbes to find the bioactive molecules (Strobel and Daisy 2003). The establishment of higher plants in their respective habitats involves a capacity to interact with different organism. The term endophytic fungus is used to describe those fungi that can be detected at a particular moment within the tissues of an apparently healthy plant host. The fungal colonization can be inter-cellular or intracellular, localized or systemic (Schulz and Boyle 2005).
An increasing number of compounds are currently being isolated from unique endophytic fungi; for example, fumitremorgins $\mathrm{B}$ has been isolated from Phomopsis sp. and periconicins A and B have been isolated from Periconia $s p$ (Isaka et al. 2001). The endophytic fungi associated with the medicinal plants not only produce antibacterial molecules but also many other pharmacologically active substances with a potential to act as antitumor agents (Pestalotiopsis microspora, taxol), antifungal agents (Cryptosporiopsis criptocandina, quercine). Endophytes are also known to produce the factors of plant growth, toxins and enzymes. Some endophytes are also used as biological controllers of many diseases and plaques (Strobel 2002).

*Author for correspondence: meenusamiksha@ rediffmail.com 
Novel enzyme systems of microbial origin also help in a better understanding of their host tissue colonization ability. Enzymes isolated from the endophytes are also used commercially in food processing, manufacturing of detergents, textiles, pharmaceutical products, medical therapy, and also in the field of Molecular biology (Falch 1991). Hence, the search for novel, natural, and efficient metabolites from the endophytes associated with unexplored and/or underexplored sources of biological diversity should be undertaken.

Bacopa monnieri (L.) Pennell (Scrophulariaceae), commonly known as "Brahmi" or Indian water hyssop is commonly found in Asia, Australia, and America. Since time immemorial, Brahmi has been used in ayurvedic formulations for treating gastrointestinal and neurologic disorders. Previous studies have proved that its active constituent bacosides enhances the efficiency of nerve impulse transmission leading to improved memory related functions (Mahato et al. 2000; Chakravarty et al. 2001; 2003; Hou et al. 2002; Russo and Borrelli 2005). There are no previous reports on the isolation and cultivation of endophytes from Bacopa monnieri. Therefore, the current study was undertaken to isolate, and screen endophytic fungi from Bacopa monnieri with antibacterial activities and also to determine their ability to produce enzymes that could be exploited industrially.

\section{MATERIAL \& METHODS}

\section{Isolation of endophytes}

Isolation of endophytic fungi from Bacopa monnieri was carried out using the protocol described by Strobel and Daisy (2003) with slight modifications. Fresh plant material (branches and leaves) was collected, washed under running tap water for $10 \mathrm{~min}$ and disinfected in series with $70 \%$ ethanol for $1 \mathrm{~min}, 1.0 \%$ sodium hypochlorite $(\mathrm{NaOCl})(\mathrm{v} / \mathrm{v})$ for $1 \mathrm{~min}$ and further cleaned by passing through two sets of sterile distilled water. After surface disinfection, leaves and branches were cut into small pieces $1 \mathrm{~cm}$ long. The disinfected samples were placed on a plate containing water agar and potato dextrose agar (PDA) media containing $250 \mu \mathrm{g} / \mathrm{mL}$ streptomycin to suppress bacterial contamination. The parafilm wrapped Petri dishes were incubated at $25 \pm 2^{\circ} \mathrm{C}$ till the fungal mycelia started growing on the samples. The endophytic fungi were purified by transferring emerging hyphae to a new potato dextrose agar slant. The isolates from the leaves of B. monnieri was codified as B1-B6, B8-B11, B13B16, B18-B19, B22-B24, B9_Pink, B8_ORG. They were stored at $4^{\circ} \mathrm{C}$; endophyte colonized sterile barley seeds were air-dried and stored at $70^{\circ} \mathrm{C}$. All the isolates were deposited in Microbial Repository of IIIM.

\section{Identification of endophytes}

The fungi were identified based on the morphological characteristic (Chen et al. 2011). Colony features were based on the observation on PDA under ambient day light conditions. Microscopic observations were made using Olympus Light Microscope model No. CH30RF200 at $400 \mathrm{x}$ or $100 \mathrm{x}$ magnification. Endophytes were identified on the basis of characteristics such as the structure of hyphae, conidia, and conidiophores. Conidiophore structure and morphology were described by obtaining them from the edge of conidiogenous pustules or fascicles during maturation of conidia, which usually occurred after 4-7 days of incubation.

\section{Phylogenetic analysis}

Phylogenetic analysis of the fungal strains was carried out on the basis of the ITS-5.8S ribosomal DNA sequences. The fungus was grown on PDA for seven days. DNA was extracted following the protocol of Raeder and Broda (1985). The ITS 5.8S rDNA region of the fungus was amplified with the universal ITS primers (1 and 2) using PCR (White et al. 1990). PCR was done as follows: $95^{\circ} \mathrm{C}$ for $5 \mathrm{~min}$, followed by 35 cycles of $94^{\circ} \mathrm{C}$ for $30 \mathrm{~s}, 55^{\circ} \mathrm{C}$ for $1 \mathrm{~min}, 72^{\circ} \mathrm{C}$ for $1 \mathrm{~min}$ and $30 \mathrm{~s}$ and a final extension for $10 \mathrm{~min}$ at $72^{\circ} \mathrm{C}$. The $50-\mu \mathrm{L}$ reaction mixture contained 1-10 $\mathrm{ng}$ of DNA, 1x PCR buffer (with $15 \mathrm{~mm} \mathrm{MgCl}_{2}$ ), 200 $\mathrm{mm}$ of each dNTP, 10 pmol of each primer (Sigma, USA) and 1U Taq DNA polymerase (Bangalore Genei, India). The amplified product $(10 \mu \mathrm{L})$ was resolved on $1 \%$ (w/v) agarose gel at $100 \mathrm{~V}$. The amplified product (approx. $500 \mathrm{bp}$ ) was eluted using a Gel extraction Kit (Qiagen, USA) and 40-60 ng was used in a $10 \mu \mathrm{L}$ sequencing reaction using Big Dye Terminator sequencing kit (v. 3.1, Applied Biosystems). The forward and reserve primers $(3.2 \mathrm{pmol})$ were used in cycle sequencing reaction. Samples were loaded on an automated sequencer (Applied 
Biosystems). The amplified products were sequenced. Resultant sequences (KF6839106KF683920) were submitted to a gene bank and were aligned with the sequences in the GenBank database via the BLASTn tool of NCBI [www.ncbi.nlm.nih.gov] (Altschul et al. 1997). Relevant sequences were downloaded and aligned using the MEGALIGN program (DNASTAR, Lasergene) and a phylogenetic tree and distance matrix were constructed according to Guindon and Gascuel (2003).

\section{Enzyme activity}

The ability to produce the following enzymes was analyzed: amylase, protease, lipase and cellulase. The enzymatic activity was studied against the test organism by agar disc diffusion method. Wells were prepared with the help of a sterilized stainless steel cork borer on the specific culture media for each enzyme to be investigated. The wells were loaded with $6 \mathrm{~mm}$ disc containing 10days old endophytic cultures. The plates were incubated at $30^{\circ} \mathrm{C}$ for $24,48,72$, and $96 \mathrm{~h}$ according to specific methodologies for each investigated enzyme and the clear halos formed were measured. The Enzymatic Index (EI) was expressed as the relationship between the average diameter of the clear halo and the average diameter of the colony growth (Hankin and Anagnostakis 1975).

\section{Amylase activity}

The amylase activity was estimated as per the methodology of Hankin and Anagnostakis (1975). Ten-days old grown endophytes plugs were spot inoculated on potato dextrose agar with $1 \%$ starch. Then the plates were treated with Gram's iodine stain for $5 \mathrm{~min}$, which allowed the visualization of clear halos around the colonies.

\section{Cellulase activity}

Ten-days old grown endophytic plugs were spot inoculated on potato dextrose agar with $1 \%$ carboxy methyl cellulose (CMC) and incubated at $28^{\circ} \mathrm{C}$ for $72 \mathrm{~h}$. Then the plates were stained with congo red (2\%) for $5 \mathrm{~min}$ followed by destaining with $1 \mathrm{M} \mathrm{NaCl}$, which allowed the visualization of clear halos around the colonies.

\section{Lipase activity}

For estimating the lipase activity, $98 \mathrm{~mL} 50 \mathrm{~mm}$ Tris $\mathrm{HCl}, \mathrm{pH} 6.8$, and $1.2 \mathrm{~g}$ agar was taken in a flask and autoclaved. In $2.0 \mathrm{~mL}$ autoclaved Tris $\mathrm{HCl}, 300 \mu \mathrm{L}$ of tributyrin (TB) and $30 \mu \mathrm{L}$ of
Tween 20 were added and mixed with Tris-agar and poured over the plates. Ten-days old grown endophytes plugs were spot inoculated on Tristributyrin agar and incubated at $28^{\circ} \mathrm{C}$ for $72 \mathrm{~h}$. Then clear halos around the colonies were observed on the plates.

\section{Protease activity}

For protease activity, ten-days old grown endophytic plugs were spot inoculated on casein starch agar with $1 \%$ skimmed milk and incubated at $30^{\circ} \mathrm{C}$ for $96 \mathrm{~h}$. After incubation, clear halos around the colonies were observed on the plates. The experiments were performed using five repetitions and the results were analyzed statistically through the variance test and the averages compared by the $\mathrm{t}$ test, the tolerance level being set at $95 \%$.

\section{Antimicrobial activity}

Lyophilized six test bacteria and one fungus were purchased from Microbial Type Culture Collection (MTCC). Cultures of Bacillus subtilis (MTCC 121), Pseudomonas aeroginosa (MTCC 424), Salmonella typhimurium (MTCC 98), Escherichia coli (MTCC 118), Klebsiella pneumonia (MTCC 109), Staphylococcus aureus (MTCC 96) were grown on Nutrient Agar media and used for measuring the antibacterial activity. Candida albicans (MTCC 183) was grown on Yeast extract Peptone Dextrose Agar (YEPD).

The antibacterial activity was studied against the test organism by agar disc diffusion method (Rios et al. 1988; Devaraju and Sreedharmurthy 2011). Wells were prepared with the help of a sterilized stainless steel cork borer and loaded with $6 \mathrm{~mm}$ disc containing 10-days old endophytic cultures. Streptomycin was used as a positive reference standard for both Gram-positive and Gramnegative bacteria whereas Amphotericin B was used as a positive reference standard for $C$. albicans (Ali et al. 2010). Each bacterial strain was inoculated into nutrient broth (HiMedia Biosciences) and incubated overnight at $37^{\circ} \mathrm{C}$ with shaking. The suspension was adjusted to 0.5 McFarland standard turbidity (equivalent to $1.5 \mathrm{x}$ $10^{8}$ colony forming units $(\mathrm{CFU} / \mathrm{mL}$ ) (Mcfarland 1987) and finally diluted to give approximately 6 x $10^{5} \mathrm{CFU} / \mathrm{mL}$ for all the organisms. One hundred microliter nutrient broth culture of each bacterial organism was used to plate on nutrient agar plates. Plates were incubated overnight and the zones of inhibition formed were measured. This experiment 
was performed in triplicate. Antibacterial activity was expressed as the diameter of the inhibition zone $(\mathrm{mm})$ produced by the endophytes and compared with the positive controls. Endophytes were considered effective when the clear zone was equal to or superior to $18 \mathrm{~mm}$ (Guimaraes et al. 2008).

\section{RESULTS AND DISCUSSION}

A total of twenty-six endophytes were isolated from B. monnieri. Seventeen of these were identified on the basis of microscopic characteristic like the structure of hyphae (Fig. 1). Further confirmation was done by ITS 5.8S ribosomal gene sequencing (Table 1). Identified endophytes included three species each from the genus Phoma, and Fusarium, two species from the genus Flavodon, one each from Alternaria sp.,
Pleosporales sp., Phomopsis, Trichoderma, Eutypella sp., Aspergillus, Fomitopsis, Myrothecium, and Colletotrichum (Table 1). Colletotrichum sp. has been implicated in many plant diseases and include some of the most destructive post-harvest pathogens of cereals, legumes, fruits and vegetables (Garcia-Pajon and Callade 2003).

\section{Phylogenetic analysis}

Phylogenetic analysis of ITS 5.8S region of endophytes divided them into five groups (Fig. 2). Out of these, four groups (Gr I-III, V) belonged to Division ascomycota and one group (Gr IV) belonged to Division basidiomycota. Group II contained the endophytes of class Dothideomycetes, whereas group III had the endophytes of class Sordariomycetes and Ascomycetes. Groups I and V had characteristics of Pleosporales sp. and Fusarium sp., respectively.

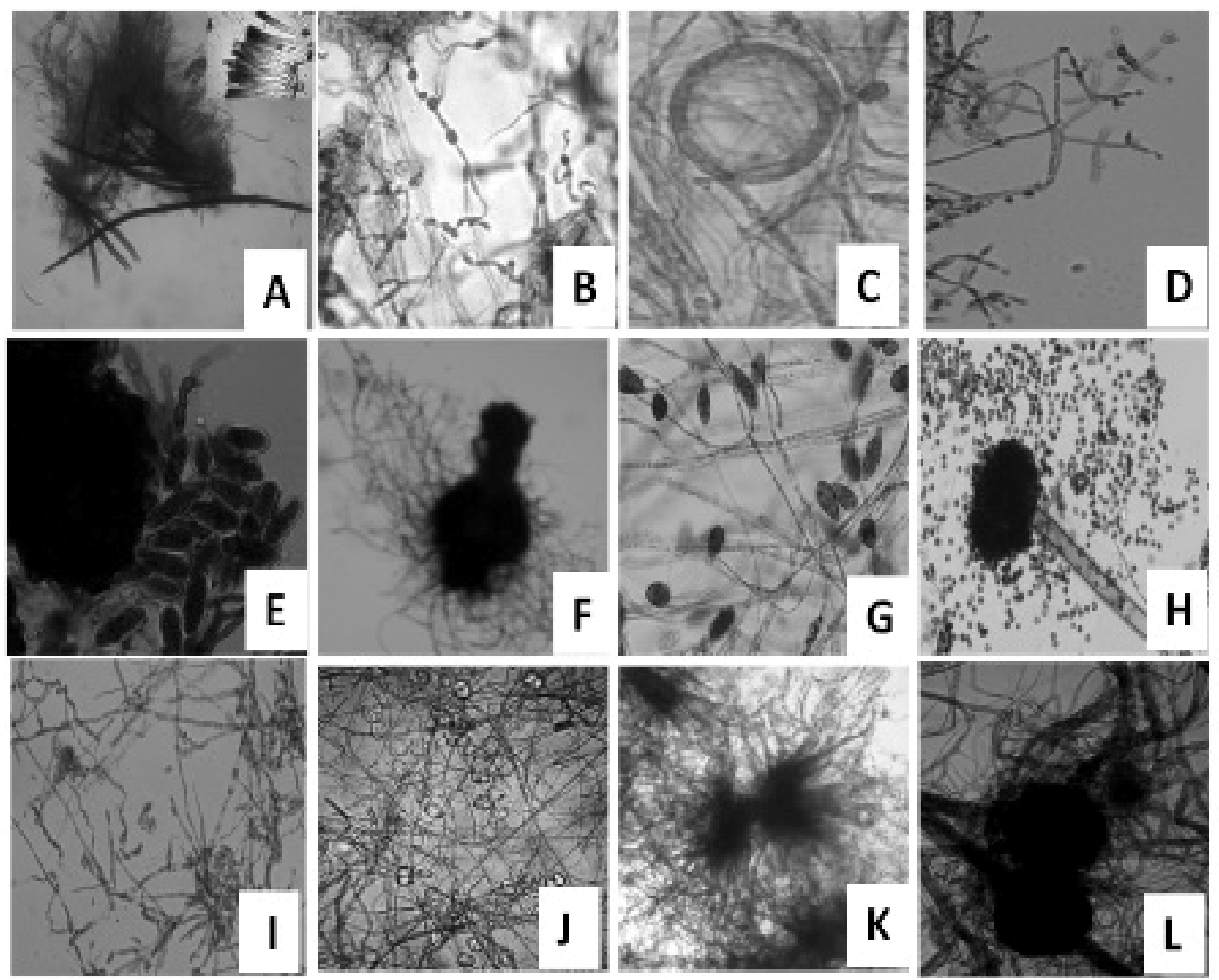

Figure 1 - Light micrographs of endophytic fungi associated with Bacopa monnieri at 400X magnification A) B1, B) B2, C) B3 D) B4, E) B8, F) B10, G) B13, H) B14, I) B16, J) B19, K) B8_ORG, L) B15. 
Table 1 - Endophytic fungi isolated from Bacopa monnieri.

\begin{tabular}{cclc}
\hline Sr. No. & Endophyte & \multicolumn{1}{c}{ Identity } & (\%) Homology \\
\hline 1 & B1 & Pleosporales $s p$. & 81 \\
2 & B2 & Phoma sp. P009 & 100 \\
3 & B3 & Flavodon flavus & 99 \\
4 & B4 & Trichoderma aureoviride & 99 \\
5 & B6 & Flavodon flavus & 99 \\
6 & B8 & Eutypella sp. E9901c & 100 \\
7 & B9 & Fusarium oxysporium & 97 \\
8 & B10 & Phoma multirostrata & 99 \\
9 & B11 & Alternaria porri & 99 \\
10 & B13 & Phoma sp. & - \\
11 & B14 & Aspergillus aculeatus & 99 \\
12 & B15 & Fungal endophyte sp. XSY14 & 98 \\
13 & B16 & Fusarium oxysporum isolate F1TK1 & - \\
14 & B18 & - & 100 \\
15 & B19 & Fomitopsis cf. meliae KYO & 99 \\
16 & B22 & Myrothecium verrucaria & - \\
17 & B23 & - & - \\
18 & B24 & - & 99 \\
19 & B9 PINK & Fusarium sp. 6241 & 100 \\
20 & B8 ORG & Colletotrichum gloeosporioides isolate OCaC4
\end{tabular}

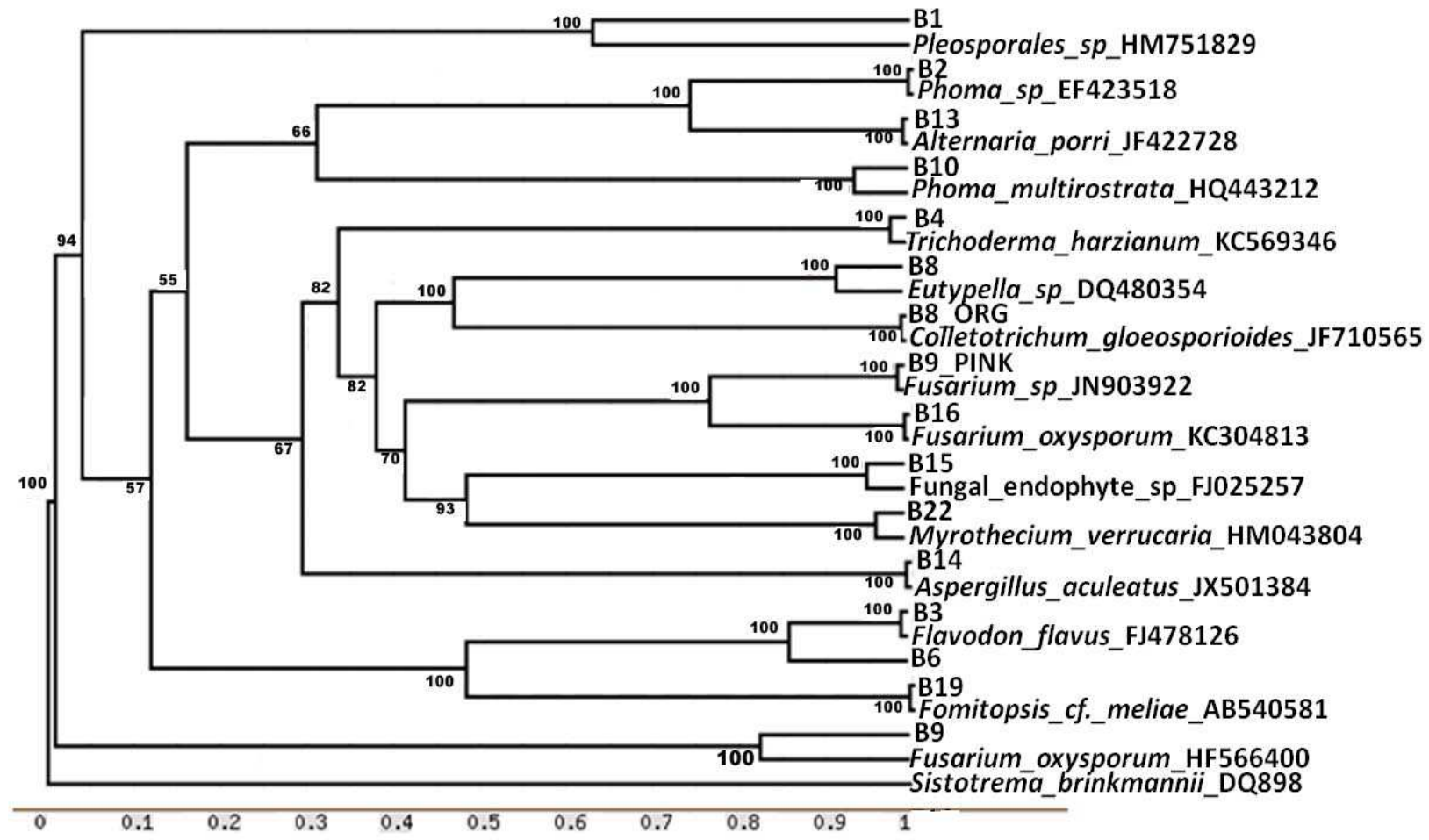

Figure 2 - Unrooted Phylogenetic Tree based on ITS-5.8S rDNA sequences of endophytic fungi associated with Bacopa monnieri showing the relative position of different fungal endophytes of this study and their close relatives. Numbers on nodes indicate bootstrap values from 1000 replicates.

\section{Enzyme activity}

Enzymatic Index (EI) values in Table 2 clearly suggested that there was a variation in the production of different extracellular enzymes by the endophytic fungi isolated from $B$. monnieri (Fig. 3). EI ranged between 2.0 to 5.33. 

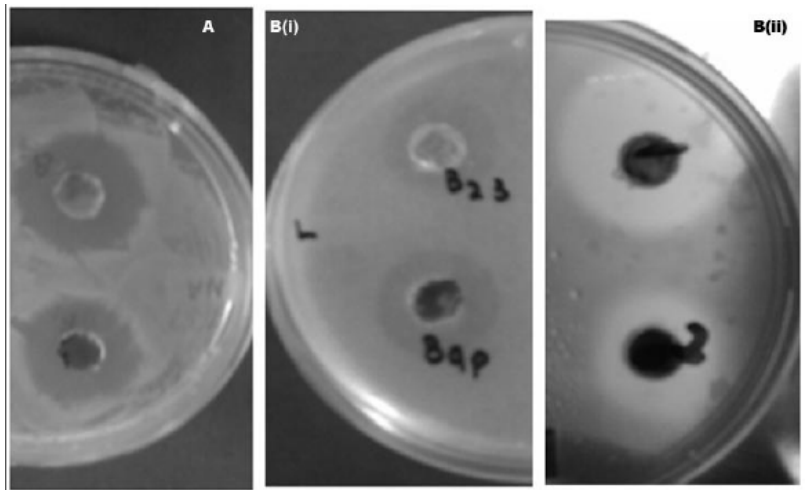

Figure 3 - A) Antimicrobial activity on nutrient-agar plate against Klebsiella pneumonia The activities were indicated by the appearance of inhibition zones (Bi) Lipolytic activity on Tris-tributyrin agar diffusion plate (Bii) Amylolytic activity on potato dextrose agar with $1 \%$ starch. The lipolytic/ amylolytic activity was determined by incubating the plates at $30^{\circ} \mathrm{C}$ for $96 \mathrm{~h}$ loaded with $6 \mathrm{~mm}$ disc containing 10 day old endophytic cultures. The lipolytic/ amylolytic activities were indicated by the appearance of clear halos.

Table 2 - Enzyme activity of the isolated endophytes from Bacopa monnieri.

\begin{tabular}{ccccc}
\hline Isolated & \multicolumn{4}{c}{ Enzymaic Index (EI) } \\
\cline { 2 - 5 } endophytes & Amylase & Lipase & Cellulase & Protease \\
\hline B1 & $\mathbf{4 . 8 3}$ & 3.33 & 0 & 2.83 \\
B2 & 3.83 & 3.416 & 0 & 2.5 \\
B3 & 3.33 & 3.083 & 0 & 3 \\
B4 & 2.83 & 2.583 & 0 & 0 \\
B6 & 3.083 & 2 & 0 & 0 \\
B8 & $\mathbf{4 . 1 6}$ & 2.83 & 0 & 2.83 \\
B9 & 2.33 & 2.66 & 0 & 0 \\
B10 & 2.33 & 2.33 & 0 & 0 \\
B11 & 3.83 & 2.916 & 0 & 0 \\
B13 & 2.66 & 2.75 & 0 & 0 \\
B14 & 2.75 & 0 & 0 & 0 \\
B15 & 3.5 & 2.66 & 0 & 0 \\
B16 & $\mathbf{4 . 4 1 6}$ & 3.166 & 3 & 0 \\
B19 & 3.66 & 2.33 & $\mathbf{5 . 3 3}$ & 3.33 \\
B22 & 3.0 & 3.33 & 3.5 & 0 \\
B23 & 2.916 & $\mathbf{4 . 2 5}$ & 3 & 0 \\
B24 & 2.5 & 3.66 & 3 & 0 \\
B9 PINK & 2.916 & 2.66 & 0 & 0 \\
B8 ORG & 3.33 & 3.083 & 2.66 & 0 \\
\hline
\end{tabular}

Amylolytic activity was observed in all the endophytic fungi (100\%). The amylolytic activity of endophytes B1, B8 and B16 (EI 4.83, 4.16, 4.416) was significantly different when compared to others. Highest amylase producers were Pleosporales sp. B1, Eutypella sp. B8 and
Fusarium oxysporum B16. Lipase activities were present in $98 \%$ of the endophytic fungi. The endophyte B23 (EI 4.25) showed significantly higher level of lipolytic activity when compared to others. It was observed that 26 and $31 \%$ of all the endophytes were able to hydrolyse cellulose and casein, respectively.

Endophyte B19 showed an EI of 5.33 and 3.33 for cellulose and casein hydrolysis, respectively. These results were significantly different when compared to others. Fomitopsis cf. meliae showed the highest zone of clearance on both CMC as well as skimmed milk plates. These results suggested that the ability to produce amylase, cellulase, lipase and protease. This could be related to the lifestyle adopted by the endophytic fungi in the host. Contrary to the results of the present study, Maria et al. (2005) reported that cellulase was produced by all the mangrove endophytic fungi of southwest coast of India, whereas amylase activity was present only in a few of those. All the endophytic fungal isolates produced proteases or/and lipases, which suggested that they might be of relevance as bio-control agents. The genetic machinery required to produce cell wall degrading enzymes such as cellulase, may already be present in endophytic fungi prior to the establishment of the symbiotic relationship with the host plant. From an evolutionary perspective, these endophytic fungal strains may have adapted to the respective metabolic machinery of the host tissues to produce biomolecules not only important for their own biology, but also for the host plant's requirements.

\section{Antimicrobial activity}

Results of antimicrobial activity are presented in Table 3 and Figure 3. All the endophytes (100\%) showed significant antimicrobial activity against $K$. pneumonia, while seventeen endophytes $(89.5 \%)$ were active against S. aureus. Fourteen endophytes (78.9\%) showed significant antimicrobial activity against $B$. subtilis and $C$. albicans. Eleven (57.8\%), nine (50\%), four (21\%) endophytes were respectively active against $S$. typhimurium, E. coli and P. aeruginosa. B4 and B19 showed IZ more than the IZ of the positive control antibiotics. 
Table 3 - Antimicrobial activity of the endophytic fungi isolated from Bacopa monnieri.

\begin{tabular}{|c|c|c|c|c|c|c|c|c|c|c|c|c|c|c|}
\hline \multirow[t]{2}{*}{$\begin{array}{c}\text { Isolated } \\
\text { endophytes }\end{array}$} & \multicolumn{2}{|c|}{$\begin{array}{l}\text { S.typhi- } \\
\text { murium }\end{array}$} & \multicolumn{2}{|c|}{ K. pneumonia } & \multicolumn{2}{|c|}{ E. coli } & \multicolumn{2}{|c|}{ B. subtilis } & \multicolumn{2}{|c|}{ P.aeroginosa } & \multicolumn{2}{|c|}{ S. aureus } & \multicolumn{2}{|c|}{ C. albicans } \\
\hline & $\begin{array}{c}\mathbf{I Z} \\
(\mathbf{m m})\end{array}$ & $\mathbf{R}$ & IZ (mm) & $\mathbf{R}$ & IZ (mm) & $\mathbf{R}$ & $\begin{array}{c}\mathbf{I Z} \\
(\mathbf{m m})\end{array}$ & $\mathbf{R}$ & IZ (mm) & $\mathbf{R}$ & IZ (mm) & $\mathbf{R}$ & IZ (mm) & $\mathbf{R}$ \\
\hline B1 & $\begin{array}{c}19 \pm 0.2 \\
8\end{array}$ & + & $27 \pm 0.58$ & + & $\begin{array}{c}21.5 \pm 0.2 \\
9\end{array}$ & + & $12 \pm 1.0$ & - & $13 \pm 0.5$ & - & $21 \pm 0.29$ & + & $23.5 \pm 0.5$ & + \\
\hline B2 & $21 \pm 1.0$ & + & $27.5 \pm 0.58$ & + & $24.5 \pm 0.5$ & + & $14 \pm 1.04$ & - & $14 \pm 1.15$ & - & $21.5 \pm 1.0$ & + & $13 \pm 0.58$ & - \\
\hline B3 & $22 \pm 0.5$ & + & $28.5 \pm 1.04$ & + & $27 \pm 0.87$ & + & $20 \pm 0.58$ & + & $22 \pm 0.17$ & + & $23 \pm 0.5$ & + & $28 \pm 0.29$ & + \\
\hline B4 & $\begin{array}{c}26 \pm 0.2 \\
9\end{array}$ & + & $28 \pm 1.0$ & + & $\begin{array}{c}25.5 \pm 0.2 \\
9\end{array}$ & + & $19 \pm 1.52$ & + & $12 \pm 1.0$ & - & $20 \pm 0.76$ & + & $22 \pm 2.5$ & + \\
\hline B6 & $16 \pm 0.5$ & - & $22 \pm 0.0$ & + & $16 \pm 1.0$ & - & $12 \pm 0.87$ & - & $17.5 \pm 0.29$ & - & $19 \pm 0.58$ & + & $27.5 \pm 1.15$ & + \\
\hline B8 & $\begin{array}{c}18 \pm 0.5 \\
8\end{array}$ & + & $32 \pm 1.15$ & + & $\begin{array}{c}16.5 \pm 0.5 \\
8\end{array}$ & - & $15 \pm 0.76$ & - & $12 \pm 0.37$ & - & $20.5 \pm 0.17$ & + & $25 \pm 1.73$ & + \\
\hline B9 & $\begin{array}{c}19 \pm 0.8 \\
7\end{array}$ & + & $31.5 \pm 0.76$ & + & $\begin{array}{c}15.5 \pm 0.7 \\
6\end{array}$ & - & $18 \pm 2.5$ & + & $16 \pm 0.58$ & - & $17 \pm 0.87$ & - & $29.5 \pm 0.17$ & + \\
\hline B10 & $20 \pm 1.0$ & + & $33 \pm 1.73$ & + & $18 \pm 1.04$ & + & $22 \pm 1.15$ & + & $14.5 \pm 0.76$ & - & $20.5 \pm 1.15$ & + & $28.5 \pm 1.0$ & + \\
\hline B11 & $\begin{array}{c}19 \pm 0.7 \\
6\end{array}$ & + & $29 \pm 1.52$ & + & $\begin{array}{c}10.5 \pm 1.1 \\
5\end{array}$ & - & $23 \pm 0.17$ & + & $17 \pm 1.73$ & - & $17.5 \pm 1.04$ & - & $18.5 \pm 0.87$ & + \\
\hline B13 & $13 \pm .28$ & - & $27 \pm 0.58$ & + & $\begin{array}{c}11.5 \pm 1.7 \\
3\end{array}$ & - & $20 \pm 1.73$ & + & $14 \pm 1.0$ & - & $18.5 \pm 0.58$ & + & $29.5 \pm 0.5$ & + \\
\hline B14 & $14 \pm 0.5$ & - & $27.5 \pm 0.5$ & + & $\begin{array}{c}11.5 \pm 1.0 \\
4\end{array}$ & - & $16 \pm 1.0$ & - & $15.5 \pm 0.5$ & - & $21 \pm 0.29$ & + & $25.0 \pm 1.15$ & + \\
\hline B15 & $\begin{array}{c}16 \pm 0.2 \\
9\end{array}$ & - & $19 \pm 2.5$ & + & $10 \pm 0.29$ & - & $20 \pm 0.76$ & + & $18 \pm 1.82$ & + & $21.5 \pm 0.76$ & + & $22 \pm 1.04$ & + \\
\hline B16 & $\begin{array}{c}20 \pm 0.8 \\
7\end{array}$ & + & $30 \pm 0.0$ & + & $18 \pm 1.52$ & + & $25 \pm 0.29$ & + & $13 \pm 0.76$ & - & $20.5 \pm 1.73$ & + & $25 \pm 0.17$ & + \\
\hline B19 & $\begin{array}{c}25 \pm 0.7 \\
6\end{array}$ & + & $27.5 \pm 0.87$ & + & $\begin{array}{c}25.5 \pm 0.1 \\
7\end{array}$ & + & $23 \pm 1.04$ & + & $13.5 \pm 0.29$ & - & $23 \pm 1.15$ & + & $11 \pm 1.0$ & - \\
\hline B22 & $\begin{array}{c}16 \pm 0.5 \\
8\end{array}$ & - & $15.5 \pm 1.0$ & - & $\begin{array}{c}16.5 \pm 1.0 \\
4\end{array}$ & - & $20 \pm 0.87$ & + & $23 \pm 0.87$ & + & $19 \pm 0.87$ & + & $13.5 \pm 0.76$ & - \\
\hline B23 & $\begin{array}{c}15 \pm 0.1 \\
7\end{array}$ & - & $19.5 \pm 0.76$ & + & $14 \pm 1.0$ & - & $23 \pm 1.15$ & + & $15.5 \pm 1.15$ & - & $19 \pm 1.0$ & + & $18.5 \pm 0.29$ & + \\
\hline B24 & $16 \pm 0.5$ & - & $21 \pm 0.17$ & + & $15 \pm 0.87$ & - & $20 \pm 0.58$ & + & $16 \pm 0.58$ & - & $24 \pm 0.17$ & + & $16 \pm 0.58$ & - \\
\hline B9 PINK & $18 \pm 1.0$ & + & $27.5 \pm 0.28$ & + & $23.5 \pm 0.5$ & + & $25 \pm 0.17$ & + & $14.5 \pm 2.5$ & - & $22 \pm 1.04$ & + & $25 \pm 1.52$ & + \\
\hline B8 ORG & $\begin{array}{c}15 \pm 0.2 \\
9\end{array}$ & - & $21.5 \pm 1.15$ & + & $22 \pm 1.15$ & + & $\begin{array}{c}27.5 \pm 0 \\
29\end{array}$ & + & $27 \pm 0.17$ & + & $27.5 \pm 0.5$ & + & $18 \pm 0.87$ & + \\
\hline Streptomycin & 20 & + & 22.5 & + & 18.7 & + & 18 & + & 25 & + & 18 & + & $*$ & \\
\hline $\begin{array}{c}\text { Amphotericin } \\
\text { B }\end{array}$ & $*$ & & * & & * & & $*$ & & $*$ & & $*$ & & 24.6 & + \\
\hline
\end{tabular}

*Not assayed R, results; + active; -inactive, IZ inhibition Zone

B8ORG showed highest activity against $B$. subtilis, $P$. aeroginosa and $S$. aureus, whereas B9 PINK and B16 showed highest activity against $K$. pneumonia, B. subtilis and C. albicans. B9 PINK showed homology with $F$. oxisporum. B1, B2 and B11 showed greatest activity against $K$. pneumonia, whereas B6 showed highest antimicrobial activity against $C$. albicans. B4 and B19 showed maximum activity against $S$. typhimurium, K. pneumonia, and E. coli, whereas B3 showed the highest activity against $K$. pneumonia, E. coli, and C. albicans. B8, B9, B10, $\mathrm{B} 13$, and B14 showed maximum activity against $K$. pneumonia, and C. albicans. B15, B22, B23 and B24 did not produce any ZI.
Endophytes have been reported as prolific producers of antimicrobial compounds. Devraju and Sreedharamurthy (2011) screened agar discs of four Fusarium sp. isolated from Mirabilis jalapa and found that Gram positive bacteria were more susceptible compared to Gram negative bacteria. Many studies have indicated that Fusarium sp. is the most common species and a potent source of bioactive compounds among the endophytes from medicinal plants. Antimicrobial compounds such as the penta-ketide (CR377: 2methylbutyraldehyde-substituted- $\alpha$-pyrone), beauvericin, subglutinol A and B from Fusrarium $\mathrm{sp}$, which were respectively isolated from Selaginella pallescens, Cinnamomum kanehirae, 
Tripterygium wilfordii plants, showed strong activity against $C$. albicans, and methicillinresistant S. aureus, respectively (Lee et al. 1995; Sean and Jon 2000; Wang et al. 2011). Similarly, altersetin from Alternaria sp., phomoxanthone A and phomoxanthone $\mathrm{B}$ and dicerandrols $\mathrm{A}-\mathrm{C}$ from Phomopsis sp. endophytes showed significant antibacterial activities (Iska et al. 2001; Wagenaar and Clardy 2001; Hellwig et al. 2002.

The relationship between the endophytes and plants is symbiotic. Endophytes produce natural products for protecting the plant host against the pests and pathogens. This is useful for the endophytes also. Natural selection is expected to favor those endophytic strains that produce such defensive chemicals for their hosts. Antimicrobial metabolites produced by the endophytes have many advantages for mankind. The endophytes are easy to be produced on a large-scale without involving the destruction of natural resources. Hence, their sustainable use is eco-friendly and quality control is easy. The continued development of new antimicrobial agents is important to overcome the difficulties related to the treatment of infections caused by the resistant pathogens, and endophytic fungi have emerged as an alternative source for the production of new antimicrobial compounds.

\section{CONCLUSIONS}

All the isolated endophytes exhibited some kind of enzymatic activity and significant antimicrobial activity against $K$. pneumonia. Some endophytes were active against $S$. aureus, B. subtilis, $C$. albicans, $S$. typhimurium, $E$. coli and $P$. aeruginosa. Endophytes, including Fusarium sp. showing significant antimicrobial and enzyme activities should be further investigated at molecule/recombinant protein level.

\section{ACKNOWLEDGEMENTS}

The research conducted in this manuscript was supported by Net-working project (BSC0117) from CSIR, Government of India. The authors are grateful to the Director of the Indian Institute of Integrated Medicine, Jammu for providing the facilities.

\section{REFERENCE}

Ali I, Khan FG, Suri KA, Gupta BD, Satti NK, Dutt P, et al. In vitro antifungal activity of hydroxychavicol isolated from Piper betle L. Ann Clin Microbiol Antimicrobiol. 2010; 9: 7

Altschul SF, Madden TL, Schaffer AA, Zhang J, Zhang Z, Miller W, et al. Gapped BLAST and PSI-BLAST: a new generation of protein database search programs. Nucleic Acids Res. 1997; 25: 3389-3402.

Chakravarty AK, Sarkar T, Masuda K, Shiojima K, Nakane T, Kawahara N. Bacopaside I and II: two pseudojujubogenin glycosides from Bacopa monniera. Phytochemistry. 2001; 58: 553-556.

Chakravarty AK, Garai S, Masuda K, Nakane T, Kawahara N. Bacopasides III-V: three new triterpenoid glycosides from Bacopa monniera. Chem Pharm Bull. 2003; 51: 215-217.

Chen J, Hu KX, Hou XQ, Guo SX. Endophytic fungi assemblages from 10 Dendrobium medicinal plants (Orchidaceae). World J Microbiol Biotechnol. 2011; 27: 1009-1016.

Devaraju R, Sreedharamurthy S. Endophytic Mycoflora of Mirabilis jalapa L. and studies on Antimicrobial activity of its endophytic Fusarium sp. Asian J Exp Biol Sci. 2011; 2: 75-79.

Falch EA. Industrial enzymes-developments in production and application. Biotechnol Adv. 1991; 9: 643-658.

Garcia-Pajon CM, Callade IG. Secondary metabolites isolated from Colletotrichum species. Nat Prod Rep. 2003; 20: 426-431.

Guimaraes DO, Borges WS, Kawano CY, Ribeiro PH, Goldman GH, Nomizo A, et al. Biological activities from extracts of endophytic fungi isolated from Viguiera arenaria and Tithonia diversifolia. FEMS Immunol Med Microbiol. 2008; 52: 134-144.

Guindon S, Gascuel O. A simple, fast, and accurate algorithm to estimate large phylogenies by maximum likelihood. Syst Biol. 2003; 52: 696-704.

Hankin L, Anagnostakis SL. The use of solid media for detection of enzyme production by fungi. Mycologia. 1975; 67: 597-607.

Hellwig V, Grothe T, Mayer-Bartschmid A, Endermann R, Geschke FU, Henkel T, et al. Altersetin, a new antibiotic from cultures of endophytic Alternaria spp. Taxonomy, fermentation, isolation, structure elucidation and biological activities. J Antibiot. 2002; 55: 881-892.

Hou CC, Lin SJ, Cheng JT, Hsu FL. Bacopaside III, Bacopa saponin $\mathrm{G}$, and bacopasides $\mathrm{A}, \mathrm{B}$, and $\mathrm{C}$ from Bacopa monniera. J Nat Prod. 2002; 65: 1759-1763.

Isaka M, Jaturapat A, Rukseree K, Danwisetkanjana K, Tanticharoen M, Thebtaranonth Y. Phomoxanthones A and B, novel xanthone dimmers from the endophytic fungus Phomopsis species. J Nat Prod. 2001; 64: 1015-1018. 
Lee JC, Lobkovsky E, Nathan BP, Strobel G, Clardy J. Subglutinols A and B: immunosuppressive compounds from the endophytic fungus Fusarium subglutinans. J Org Chem. 1995; 60: 7076-7077.

Mc Farland J. Standardization of bacterial culture for the disc diffusion assay. J Amer Med Assoc. 1987; 49: 1176-1178.

Maria GL, Sridhar KR, Raviraja NS. Antimicrobial and enzymatic activity of mangrove endophytic fungi of southwest coast of India. J Agril Technol. 2005; 1: 67-80.

Mahato SB, Garai S, Chakravarty AK. Bacopasaponins $\mathrm{E}$ and $\mathrm{F}$ : two jujubogenin bisdesmosides from Bacopa monniera. Phytochemistry. 2000; 53: 711714.

Raeder U, Broda P. Rapid preparation of DNA from filamentous fungi. Lett Appl Microbiol. 1985; 1: 1720.

Rios JL, Recio MC, Villar A. Screening methods for natural products with antimicrobial activity: a review of the literature. J Ethanopharmacol. 1988; 23: 127149.

Russo A, Borrelli F. Bacopa monniera, a reputed nootropic plant: An overview. Phytomed. 2005; 12: 305-317

Schulz B, Boyle C. The endophytic continuum. Mycol Res. 2005; 109: 661-686.
Sean FB, Jon C. CR377, a new petaketide antifungal agent isolated from an Endophytic fungus. $J$ Nat Prod. 2000; 3: 1447-1448.

Strobel GA, Daisy B. Bioprospecting for microbial endophytes and their natural products. Microbiol Mol Biol Rev. 2003; 67: 491-502.

Strobel GA. Rainforest endophytes and bioactive products. Crit Rev Biotechnol. 2002; 22: 315-333.

Wagenaar MM, Clardy J. Dicerandrols, new antibiotic and cytotoxic dimmers produced by the fungus Phomopsis longicolla isolated from an endangered mint. J Nat Prod. 2001; 64: 1006-1009.

Wang QX, Li SF, Zhao F, Dai HQ, Bao B, Ding R, et al. Chemical constituents from endophytic fungus Fusarium oxysporum. Fitoterapia. 2011; 82: 777781.

White TJ, Bruns T, Lee S, Taylor J. Amplification and direct sequencing of fungal ribosomal RNA genes for phylogenetics. In: Innis M, Gelfand D, Sninsky J, White T. editor. PCR protocols: a guide to methods and applications. Academic Press, San Diego, 1990. P. 315-322. 